\title{
Thermo-Hydromechanical Coupling Responses Driven by a Central Heat Source in Unsaturated Soils
}

\author{
Wei Wang, ${ }^{1}$ Jingjing Liu, ${ }^{1}$ and Jing Chen $\mathbb{D}^{2}$ \\ ${ }^{1}$ China Hebei Construction and Geotechnical Investigation Group Ltd., Shijiazhuang 050227, China \\ ${ }^{2}$ School of Civil Engineering, Beijing Jiaotong University, Beijing 100044, China \\ Correspondence should be addressed to Jing Chen; 20121024@bjtu.edu.cn
}

Received 4 January 2022; Accepted 18 January 2022; Published 4 February 2022

Academic Editor: Yonghong Wang

Copyright (c) 2022 Wei Wang et al. This is an open access article distributed under the Creative Commons Attribution License, which permits unrestricted use, distribution, and reproduction in any medium, provided the original work is properly cited.

Based on the thermodynamic and thermoelastic theory, the coupled governing equations of deformation, heat transfer, and moisture migration in unsaturated soils were given. The coupled calculation process was realized by the finite element method. The hydrothermal coupling characteristics of two cases of unsaturated kaolin clay were studied by using a self-developed test device, and the test results were compared with the numerical results. The results showed that when the initial saturation of the soil is high, the volumetric water content of the measured point increases, and then it is in a stable state during the heating process. When the initial saturation is low, the volumetric water content near the heat source increases firstly and then decreases during the heating process. The rise and fall of temperature make the volumetric water content of the soil irreversible. The volumetric water content of each measured point is lower than the initial state. The closer it is to the internal measured heat source, the more obvious this phenomenon is; the lower the initial saturation is, the more obvious it is.

\section{Introduction}

The study on the unsteady responses of internal temperature transfer and moisture migration induced by the coupling effect of suction potential, gravitational potential, and temperature potential in unsaturated soils has very important significance. The application respects are involved in geothermal resource development [1], thermal energy storage [2], nuclear waste disposal [3], and heating pipeline design [4]. The study mainly relates to the coupling of different physical fields, for instance, hydraulic and mechanical thermal responses.

In order to analyse the responses of various physical fields, scholars have studied them from different angles. Chen et al. [5] constructed a complicated multifield coupling model for unsaturated porous media considering chemical and hydration swelling effects based on mixture coupling theory, nonequilibrium dynamics, and Biot's elastic theory. Chen et al. [6] proposed a method for analysing thermo-hydromechanical processes in porous media based on the continuum mechanics of the conservation of momentum, energy, and mass and the averaging method in the three-phase mixture theory (solid-liquid-gas) system. This model considered the effects of stress-strain, water-air-vapour phase flow, thermal transfer, and porosity evolution on the coupled response. Rutqvist et al. [7] gave basic governing equations of the thermo-hydromechanical coupling process of unsaturated fractured rock and soil and compared four finite element programs. Chen et al. [8] conducted experimental evaluations on several models describing the relationship between permeability and capillary pressure-saturation, which showed that LNM, VGM, GDM, and BRB models can better describe the flow of two-phase fluids. Wu et al. [9] established a coupled thermo-hydromechanical stress-strain relationship of unsaturated soils, which can describe the influence of heat on the hydraulic characteristics of soils and can quantitatively simulate thermal softening phenomena. Finally, the test results were compared with the numerical simulation results. Akrouch et al. [10] discussed the coupled hydrothermal characteristics of energy piles to unsaturated soils by experiments, theory, and numerical simulation and compared the experimental results with analytical and finite element 
solutions. Ghorbani et al. [11] established a theory that can describe the hydraulic interaction behavior for typical unsaturated soils under static and dynamic loads on the basis of previous studies. By solving the dynamic problems of unsaturated soils with elastic frameworks and nonlinear frameworks, the static problem of the saturated soil verified the correctness of the established model.

Bai [12] discussed the semianalytical solutions of porous and saturated spheres with cavities under several boundary conditions and compared the effects of thermal response on field variables such as radial displacement, pore pressure, and tangential or radial stress through numerical analysis, which is a pioneering work. Caulk et al. [13] proposed a pore-scale numerical method for simulating the thermohydromechanical coupling behavior of granular media on the basis of the existing fluid mechanics model. For unsaturated soils, Takayama et al. [14] established a constitutive model based on the Cambridge model to describe the changes of the mechanical properties in view of bentonite in the nuclear waste repository due to the hydration process. Zeng et al. [15] established a vertical one-dimensional, mass flow heat, and two-phase model considering diffusion, advection, and dispersion and used the model to discuss the advection effects of high-permeability soil as well as lowpermeability soil. For saturated porous media, Bai [16] established a normalized coupled governing equation and discussed the theoretical response under cyclic thermal load for one-dimensional cyclic thermal consolidation. Among these, the evolution process of displacement, pore pressure, and temperature from an unsteady state (i.e., instantaneous state) to a quasi-steady state was analysed. An et al. [17] established a two-dimensional hydrothermal coupling model and used meteorological data to estimate the surface heat flow and water flow boundary. On this basis, the variation rules of temperature as well as the volumetric water content of embankment were also studied. Zhou and Ng [18] established a new coupled thermomechanical theory of saturated soil based on the boundary surface plasticity theory. The shape and size of the boundary surface of this theoretical model can change with temperature, which can predict the elastic-plastic response of saturated soil under small deformation. For unsaturated porous media, the multifield coupling process is greatly affected by saturation degree. The effect of saturation on the coupled thermohydromechanical process in porous media is of great significance to understand the properties of the multifield coupling response, even including the influence of chemical factors [19-21]. However, all the constitutive models described above are derived based on the general elastic-plastic theory.

In this paper, the relationship between the degree of saturation and pore gas pressure as well as pore water pressure in the soil-water characteristic curve [22] is utilized to derive the seepage equation of unsaturated porous media through the continuity equation of pore water and pore gas. Based on the combination of thermodynamics and thermoelastic theory, the governing equations with coupled thermo-hydromechanical characteristics as well as state equations of the water-gas two-phase flow in porous media are further given. The coupling calculation process is realized by the finite element method. Then, a self-developed test device was utilized to analyse the hydrothermal coupling characteristics of two different unsaturated kaolin clay under the same temperature load, and the obtained experimental results verified the rationality of the proposed theoretical model. This work provides further insight into the hydrothermal effects of kaolin soil from the multifield coupling point of view.

\section{Coupled Governing Equations for Unsaturated Soils}

2.1. Seepage Differential Equation. Under the condition of ignoring the evaporation of water in porous media, the mass conservation equation of pore water, pore gas, and solid matrix can be expressed as $[7,8]$

$$
\begin{array}{r}
\frac{\partial\left(n S_{w} \rho_{w}\right)}{\partial t}+\nabla \cdot\left(n S_{w} \rho_{w} \cdot v_{w}\right)=0, \\
\frac{\partial\left(n S_{g} \rho_{g}\right)}{\partial t}+\nabla \cdot\left(n S_{g} \rho_{g} \cdot v_{g}\right)=0, \\
\frac{\partial\left((1-n) \rho_{s}\right)}{\partial t}+\nabla \cdot\left((1-n) \rho_{s} \cdot v_{s}\right)=0,
\end{array}
$$

where $\nabla \cdot$ is the divergence calculation; $n$ is the porosity of the porous medium; $\rho_{w}, \rho_{s}$, and $\rho_{g}$ are the density of pore water, solid matrix, and pore gas $\left(M L^{-3}\right)$, respectively; $S_{w}$ and $S_{g}$ are pore water and pore gas saturation; and $v_{w}, v_{s}$, and $v_{g}$ are the velocity vectors of pore water, solid substrate, and pore gas $\left(L T^{-1}\right)$, respectively.

Considering the effect of gravity, the velocity of the pore water as well as pore gas phase to the solid substrate can be expressed as [23-26]

$$
\left\{\begin{array}{l}
v_{r w}=v_{w}-v_{s}, \\
v_{r g}=v_{g}-v_{s}, \\
\nabla \cdot v_{s} \approx \frac{\partial \varepsilon_{v}}{\partial t}
\end{array}\right.
$$

According to [27-31],

$$
\begin{aligned}
& n S_{w} v_{r w}=-\frac{K \cdot K_{r w}}{\mu_{w}} \cdot\left(\nabla P_{w}+\rho_{w} g \cdot \nabla z\right)=u_{w}, \\
& n S_{g} v_{r g}=-\frac{K \cdot K_{r g}}{\mu_{g}} \cdot\left(\nabla P_{g}+\rho_{g} g \cdot \nabla z\right)=u_{g},
\end{aligned}
$$

where $K$ is the porous medium permeability $\left(L^{2}\right) ; \mu_{w}$ and $\mu_{g}$ are the pore water and pore gas viscosity $\left(M L^{-1} T^{-1}\right)$, respectively; $K_{r w}$ and $K_{r g}$ are the relative permeability of the liquid and gas phase, respectively; $P_{w}$ and $P_{g}$ are the pore water and pore gas pressure $\left(M L^{-1} T^{-2}\right) ; v_{r w}$ and $v_{r g}$ are the relative velocity of the liquid and gas phase, respectively; $z$ is the height relative to the reference plane; $g$ is the gravitational acceleration; $u_{g}$ and $u_{w}$ are the average relative flow 
rates of pore gas and pore water $\left(L T^{-1}\right)$ in the cross section of the porous medium, respectively.

According to [32-36], it can be known that pore water saturation should be a function of temperature and matrix suction, which has the following relationship:

$$
\left\{\begin{array}{l}
S_{w}=S_{w}\left(P_{c}, T\right), \\
S_{g}=1-S_{w}, \\
P_{c}=P_{g}-P_{w},
\end{array}\right.
$$

where $T$ is the current absolute temperature and $P_{c}$ is the matrix suction $\left(M L^{-1} T^{-2}\right)$.

Then, the derivative of the saturation of pore water $S_{w}$ with respect to time is

$$
\begin{aligned}
\frac{\partial S_{w}}{\partial t}= & \frac{\partial S_{w}}{\partial P_{c}} \frac{\partial P_{c}}{\partial t}+\frac{\partial S_{w}}{\partial T} \frac{\partial T}{\partial t}=C_{P} \frac{\partial P_{g}}{\partial t}-C_{P} \frac{\partial P_{w}}{\partial t} \\
& +C_{T} \frac{\partial T}{\partial t}=-\frac{\partial S_{g}}{\partial t},
\end{aligned}
$$

where $C_{P}$ and $C_{T}$ are the water-holding characteristic coefficients of capillary action $\left(M^{-1} L T^{2}\right)$ and temperature action $\left(\theta^{-1}\right)$, respectively, which are determined by the soilwater characteristic curve.

Substituting equations (4)-(8) into equations (1) and (2), the seepage differential equations of pore water as well as pore gas can be obtained as follows:

$$
\begin{gathered}
n \rho_{w} C_{P} \frac{\partial P_{w}}{\partial t}-\nabla \cdot\left(-\rho_{w} \frac{K K_{r w}}{\mu_{w}}\left(\nabla P_{w}+\rho_{w} g \cdot \nabla z\right)\right)=n \rho_{w} C_{P} \frac{\partial P_{g}}{\partial t} \\
+n \rho_{w} C_{T} \frac{\partial T}{\partial t}+n S_{w} \frac{\partial \rho_{w}}{\partial t}+S_{w} \rho_{w}\left[\frac{(1-n)}{\rho_{s}} \frac{\partial \rho_{s}}{\partial t}+\frac{\partial \varepsilon_{v}}{\partial t}\right] \\
n \rho_{g} C_{P} \frac{\partial P_{g}}{\partial t}-\nabla \cdot\left(-\rho_{g} \frac{K K_{r g}}{\mu_{g}}\left(\nabla P_{g}+\rho_{g} g \cdot \nabla z\right)\right)=n \rho_{g} C_{P} \frac{\partial P_{w}}{\partial t} \\
-n \rho_{g} C_{T} \frac{\partial T}{\partial t}+n S_{g} \frac{\partial \rho_{g}}{\partial t}+S_{g} \rho_{g}\left[\frac{(1-n)}{\rho_{s}} \frac{\partial \rho_{s}}{\partial t}+\frac{\partial \varepsilon_{v}}{\partial t}\right]
\end{gathered}
$$

2.2. Momentum Conservation Equation. For unsaturated porous media, the momentum conservation equation without considering the inertial force can be expressed as $[7,8]$

$$
\nabla \cdot \sigma+\left[(1-n) \rho_{s}+n S_{w} \rho_{w}+n S_{g} \rho_{g}\right] \cdot g=0 .
$$

Considering the skeleton deformation, thermal strain, wet strain, pore pressure deformation, and equivalent stress principles of porous media, the stress-strain relationship is

$$
\sigma=D:\left(\varepsilon-\varepsilon_{T}-\varepsilon_{S}-\varepsilon_{P}\right)-I \bar{P},
$$

where

$$
\left\{\begin{array}{l}
\varepsilon_{T}=\beta_{T}\left(T-T_{0}\right), \\
\varepsilon_{S}=\beta_{M}\left(S_{w}-S_{w 0}\right), \\
\varepsilon_{P}=-\frac{\bar{P}-\bar{P}_{0}}{3 K_{m}}, \\
\bar{P}=S_{w} P_{w}+S_{g} P_{g},
\end{array}\right.
$$

where $\beta_{T}$ and $\beta_{M}$ are the linear thermal expansion coefficient and linear wet expansion coefficient of the porous solid matrix, respectively; $D$ is the tangential stiffness matrix, which is the weighted average pore pressure $\left(M L^{-1} T^{-2}\right) ; S_{w 0}$ and $T_{0}$ are the initial saturation and initial temperature, respectively; and $K_{m}$ is the bulk modulus of the matrix of the porous medium $\left(M L^{-1} T^{-2}\right)$.

2.3. Energy Conservation Equation. Considering the change rate of thermal strain and wet strain energy, for unsaturated porous media, the energy conservation equation can be expressed as $[7,8]$

$$
\begin{aligned}
\frac{\partial}{\partial t} & {\left[n S_{w} \rho_{w} e_{w}+n S_{g} \rho_{g} e_{g}+(1-n) \rho_{s} e_{s}\right]+(1-n) 3 K_{m}\left(\beta_{T} T+\beta_{M} S_{w}\right) \frac{\partial \varepsilon_{v}}{\partial t} } \\
& +\nabla \cdot\left(k_{t} \cdot \nabla T\right)+\left(n S_{w} P_{w} \nabla \cdot v_{w}+n S_{g} P_{g} \nabla \cdot v_{g}\right) \\
& +\nabla \cdot\left[h_{w} n S_{w} \rho_{w} \cdot v_{w}+h_{g} n S_{g} \rho_{g} \cdot v_{g}+h_{s}(1-n) \rho_{s} \cdot v_{s}\right]=Q
\end{aligned}
$$

where $e_{w}, e_{g}$, and $e_{s}$ are the internal energy per unit mass of pore water, pore gas, and solid matrix $\left(L^{2} T^{-2}\right)$, respectively, $e=c_{v} \cdot\left(T-T_{0}\right) ; h_{w}, h_{g}$, and $h_{s}$ are the heat content of pore water, pore gas, and solid matrix per unit mass, respectively $\left(L^{2} T^{-2}\right) ; Q$ is the total heat source intensity $\left(L^{-1} M T^{-3}\right) ; k_{t}$ is the total thermal conductivity of porous media $\left(M T^{-3} \theta^{-1}\right) ; c_{v}$ and $c_{p}$ are the specific heat of constant volume and pressure, respectively $\left(L^{2} T^{-2} \theta^{-1}\right)$; and $\gamma$ is the specific heat rate.
On the left side of equation (13), the first term is the change rate of the internal energy of the system, the second term is the change rate of reversible elastic energy caused by the solid phase change [37-40], the third term is the heat conduction, the fourth term is the energy change produced by pore water pressure [41-44], and the fifth term is the difference between the incoming and outgoing energy per unit time. 
According to previous studies [45-49], considering the effects of saturation and porosity degree on the effectivity of the thermal conductivity, the total thermal conductivity can be expressed as

$$
k_{t}=n\left[\frac{a_{1}\left(k_{w}-k_{g}\right) S_{w}}{1+a_{2} S_{w}}+k_{g}\right]+(1-n) k_{s},
$$

where $k_{s}, k_{g}$, and $k_{w}$ are the thermal conductivity of the porous media matrix, pore gas, and pore water $\left(M T^{-3} \theta^{-1}\right)$ and $a_{1}$ and $a_{2}$ both are experimental fitting parameters, respectively.

2.4. Water Retention Characteristics. In view of the VG model [50-53], the relationship between matrix suction and relative permeability and relative effective saturation can be expressed as

$$
\begin{aligned}
& S_{e w}= \begin{cases}\frac{1}{\left[1+\left(\alpha H_{C}\right)^{n}\right]^{m}} & \left(H_{C}>0\right) \\
1 & \left(H_{C} \leq 0\right)\end{cases} \\
& H_{C}=\frac{P_{c}}{\rho_{w} g}, \\
& K_{r w}= \begin{cases}S_{e w}^{L}\left[1-\left(1-S_{e w}^{1 / m}\right)^{m}\right]^{2} & \left(H_{C}>0\right), \\
0 & \left(H_{C} \leq 0\right),\end{cases} \\
& K_{r g}= \begin{cases}\left(1-S_{e w}\right)^{L}\left(1-S_{e w}^{1 / m}\right)^{2 m} & \left(H_{C}>0\right) \\
1 & \left(H_{C} \leq 0\right)\end{cases}
\end{aligned}
$$

where $S_{e w}$ is the relative effective saturation; $m$ and $n$ are the fitting parameters, where $m$ is related to the asymmetry of the soil-water characteristic curve and $n$ is related to the slope of the curve; and $H_{c}$ is the matrix suction head.

Pore water saturation degree can be written as

$$
S_{w}=S_{w r}+\left(S_{w s}-S_{w r}\right) S_{e w}
$$

where $S_{w r}$ and $S_{w s}$ are the residual saturation and maximum saturation, respectively.

According to equation (8), it is assumed that the parameters $\alpha, m$, and $L$ have approximately linear relationships with temperature, which can be commonly written as

$$
\left\{\begin{array}{l}
\frac{\alpha}{\alpha_{0}}=1+C_{\alpha T}\left(T-T_{0}\right), \\
\frac{m}{m_{0}}=1+C_{m T}\left(T-T_{0}\right), \\
\frac{L}{L_{0}}=1+C_{L T}\left(T-T_{0}\right) .
\end{array}\right.
$$

When $H_{c}>0$, according to equations (8), (14), (15), and (16), one has

$$
\begin{aligned}
C_{P}= & \frac{\partial S_{w}}{\partial t}=\frac{-\alpha m\left(S_{w s}-S_{w r}\right)}{\rho_{w} g(1-m)} S_{e w}^{1 / m}\left(1-S_{e w}^{1 / m}\right)^{m}, \\
C_{T}= & \frac{\partial S_{w}}{\partial T}=C_{m T} \frac{m_{0} S_{w}\left(S_{w s}-S_{w r}\right)}{1-m}\left[\left(\frac{1}{m}-S_{w}^{1 / m}\right) \ln S_{w}-m\left(1-S_{w}^{1 / m}\right) \ln \left(1-S_{w}^{1 / m}\right)\right] \\
& -C_{\alpha T} \frac{\alpha_{0} m S_{w}\left(S_{w s}-S_{w r}\right)}{\alpha(1-m)}\left(1-S_{w}^{1 / m}\right) .
\end{aligned}
$$

2.5. State Equations. In order to simulate the real situation effectively, each state quantity adopts a nonlinear calculation formula related to temperature. According to [54-56], the density $\rho$ of pore gas, pore water, and solid matrix, the viscosity coefficient of pore gas and pore water $\mu(\mathrm{Pa} \cdot \mathrm{s})$, the heat capacity at constant pressure $c_{p}(\mathrm{~J} /$ $(\mathrm{kg} \cdot \mathrm{K}))$, and thermal conductivity $k(\mathrm{~W} /(\mathrm{m} \cdot \mathrm{K}))$ can be expressed as, respectively, 


$$
\begin{aligned}
& \rho_{w}=838.47+1.40 T-0.003 T^{3}+3.72 \times 10^{-7} T^{3}, \\
& \rho_{g}=\frac{P_{g}}{R_{g} T} \\
& \rho_{s}=\rho_{s 0}\left[1+\frac{\bar{P}-\bar{P}_{0}}{K_{m}}-3 \beta_{T}\left(T-T_{0}\right)-3 \beta_{M}\left(S_{w}-S_{w 0}\right)-\frac{\operatorname{tr}\left(\sigma^{\prime}-\sigma_{0}^{\prime}\right)}{3 K_{m}(1-n)}\right] \\
& \mu_{w}=1.38-0.02 T+1.36 T^{2}-4.65 \times 10^{-7} T^{3}+8.90 \times 10^{-10} T^{4} \\
& -9.08 \times 10^{-13} T^{5}+3.85 \times 10^{-16} T^{6} \\
& (273.15 K<T<413.15 K) \text {, } \\
& \mu_{g}=-8.38 \times 10^{-7}+8.36 \times 10^{-8} T-7.69 \times 10^{-11} T^{2}+4.64 \times 10^{-14} T^{3} \\
& -1.07 \times 10^{-17} T^{4} \\
& (203.15 K<T<1573.15 K) \text {, } \\
& c_{p w}=12010.15-80.41 T+0.31 T^{2}-5.38 \times 10^{-4} T^{3}+3.63 \times 10^{-7} T^{4} \\
& (273.15 K<T<553.15 K) \text {, } \\
& c_{p g}=1047.64-0.37 T+9.45 \times 10^{-4} T^{2}-6.02 \times 10^{-7} T^{3}+1.29 \times 10^{-10} T^{4} \\
& (203.15 K<T<1573.15 K) \text {, } \\
& k_{w}=-0.87+8.95 \times 10^{-3} T-1.58 \times 10^{-5} T^{2}-7.98 \times 10^{-9} T^{3} \\
& (273.15 K<T<553.15 K) \text {, } \\
& k_{g}=-2.28 \times 10^{-3}+1.16 \times 10^{-4} T-7.90 \times 10^{-8} T^{2}-4.12 \times 10^{-11} T^{3} \\
& -7.44 \times 10^{-15} T^{4} \\
& (203.15 K<T<1573.15 K) \text {, }
\end{aligned}
$$

where

$$
\begin{aligned}
\operatorname{tr}\left(\sigma^{\prime}-\sigma_{0}^{\prime}\right)= & 3 K_{b} \varepsilon_{v}+3 \frac{K_{b}}{K_{m}}\left(\bar{P}-\bar{P}_{0}\right) \\
& -9 K_{b} \beta_{T}\left(T-T_{0}\right)-9 K_{b} \beta_{M}\left(S_{w}-S_{w 0}\right),
\end{aligned}
$$

where $R_{g}$ is actually the gas constant of air $\left(L^{2} T^{-2} \theta^{-1}\right) ; \sigma^{\prime}$ is the effective stress acting on the matrix in the porous medium $\left(L^{-1} M T^{-2}\right)$, in which $\sigma_{0}^{\prime}$ is the initial value of the effective stress $\left(L^{-1} M T^{-2}\right) ; \rho_{s 0}$ is the initial density of the porous medium matrix $\left(M L^{-3}\right)$; and $\operatorname{tr}(\cdot)$ is the trace operation in mathematics.

According to equations (3), (11), and (19), the porosity can be expressed as

$$
n=1-\frac{\left(1-n_{0}\right) e^{\varepsilon_{v 0}-\varepsilon_{v}}}{1+\left(\bar{P}-\bar{P}_{0} / K_{m}\right)-3 \beta_{T}\left(T-T_{0}\right)-3 \beta_{M}\left(S_{w}-S_{w 0}\right)-\left(\operatorname{tr}\left(\sigma^{\prime}-\sigma_{0}^{\prime}\right) / 3 K_{m}(1-n)\right)}
$$




\section{Laboratory Model Experiment}

3.1. Test Apparatus Description. A test device with a cylindrical chamber is used to study the water-heat coupling effect in unsaturated soils, as shown in Figure 1. The upper and lower ends of the test device are fixedly connected with the stainless steel plate through movable bolts, and an $\mathrm{O}$-shaped rubber ring is set for sealing treatment. The test device is made of stainless steel (304 stainless steel), with an inner radius of $R=50 \mathrm{~cm}$, a cylinder of $1 \mathrm{~cm}$ wall thickness, and a height of $H=50 \mathrm{~cm}$. In order to meet the axisymmetric temperature, hydraulic, deformation, and migration boundary conditions, the stainless steel bottom plate and top cover are inlaid with a heat-insulating and impervious PC board. A layer of asbestos material is placed between the top cover and the bottom plate and the PC board. The centre of the test device is a cylindrical heat source $T_{\text {in }}$ with a radius of $r=2 \mathrm{~cm}$, whose temperature is applied by using a constant temperature water bath circulation device, which can provide a long-term constant temperature possessing an accuracy of $\pm 0.1^{\circ} \mathrm{C}$. Besides, the outer temperature boundary of the test device also circulates through the constant temperature water bath. The device is applied and set to $T_{\text {out }}=25^{\circ} \mathrm{C}$.

In order to analyse the heat-water coupling effect in unsaturated soils, temperature sensors ( $K$-type thermocouples) and volumetric water content sensors (EC-5) were embedded at different radial distances on the middle plane of the soil during the filling process of the soil sample, as shown in Figure 1. Four measuring points of temperature and moisture were arranged from the edge of the test tube to the centre, with an interval of $10 \mathrm{~cm}$. By the temperature and moisture collector, the moisture and temperature changes at different locations were recorded in real time.

3.2. Test Schemes. In the experiment, washed kaolin clay from Lingshou County, Hebei Province, China, was used as the porous medium, and the relevant property parameters are shown in Table 1. A mortar mixer is used to mix kaolin clay with a particle size of $37.5 \mu \mathrm{m}$ into two different saturation degrees. Through experiments, the changes in temperature and seepage field of kaolin clay with two different saturation degrees are studied during the heating and cooling process. The two cases include (1) the kaolin sample with the initial saturation of 0.47 (mass moisture content 0.130 ), the internal temperature boundary of $80^{\circ} \mathrm{C}$, and the outer temperature boundary of $25^{\circ} \mathrm{C}$. The coupled properties of the seepage and temperature field during the heating process are studied. Both internal and external temperature boundaries are at $25^{\circ} \mathrm{C}$. Meanwhile, the coupling response of seepage and temperature field is considered during the cooling process; (2) the initial saturation of the kaolin sample is 0.29 (mass moisture content 0.08 ), the internally measured temperature boundary is $80^{\circ} \mathrm{C}$, and the outer temperature boundary is $25^{\circ} \mathrm{C}$. The schemes are emerged in Table 2.

\section{Results and Discussion}

4.1. Physical Model and Boundary Conditions. This paper uses "COMSOL Multiphysics 5.6" finite element software to solve the governing equations in Section 2 and to simulate the experimental process. The calculation model adopts an axisymmetric model. The inner heat source and the outer cylindrical wall were set as impervious and incapable of displacement boundary conditions; the top cover and bottom plate were set as thermally insulated with impervious boundary conditions. The temperature boundary of the inner heat source was set to $80^{\circ} \mathrm{C}$ and $25^{\circ} \mathrm{C}$ during the rising and falling process. The temperature boundary of the outer cylindrical wall was set to $25^{\circ} \mathrm{C}$, and the initial temperature of the soil was $25^{\circ} \mathrm{C}$. Thus, the optimization results of relevant parameters required in the calculation are shown in Table 3. The model mesh was divided into a free triangle mesh, the maximum element size was $2.65 \mathrm{~cm}$, and the minimum element size was $0.15 \mathrm{~mm}$ (Figure 2). The complete grid contains a total of 884 domain elements and 74 boundary elements.

In the calculation process, both the internal heat source temperature boundary $T_{\text {in }}$ and the outer temperature boundary $T_{\text {out }}$ were set as the first type of boundary conditions. As a result, the internal heat source temperature boundary is within the first $5.15 \mathrm{~d}$, and the temperature was maintained at about $80^{\circ} \mathrm{C}$. During the test, the temperature was basically maintained at about $25^{\circ} \mathrm{C}$. It should be noted that, during the $5.15 \mathrm{~d}$ cooling process, the water bath needs to be replaced with cold water to achieve the cooling effect. The constant temperature water bath had no cooling function, so the internal temperature of the heat source was measured. After the temperature drop starts, it first rises and then gradually decreases to $25^{\circ} \mathrm{C}$, as shown in Figure 3(a), while the outer temperature boundary has been maintained at about $25^{\circ} \mathrm{C}$ (Figure 3(b)), which was arranged on the outer cylindrical wall of the test device (Figure 3(b)). The temperature measured by sensors changes over time at four different locations.

4.2. Discussion. According to the test results, it can be found that the volumetric water content of each monitoring position in the soil has changed after the temperature rising and falling process. Due to different soilwater characteristics of unsaturated soils in the process of moisture absorption and dedrying, the VG model parameters are different during the heating and cooling processes. After trial calculations, the parameter $\alpha_{1}=1.89 \mathrm{~m}^{-1}$ during the heating process; it is taken as $\alpha_{2}=1.93 \mathrm{~m}^{-1}$ during the cooling process. In the calculation process, the initial pore water pressure as well as pore gas pressure was $0.94 \times 105 \mathrm{~Pa}$ and $1.01 \times 105 \mathrm{~Pa}$, respectively. Figure 3 shows the comparison between the calculated results and the experimental results of the volumetric water content at different monitoring positions in the soil for case 1 . By comparison, it can be observed that the calculation results are consistent with the experimental results. During the heating process, the calculation results of positions $B_{1}, C_{1}$, and $D_{1}$ are in good agreement with the test results, while the calculation results of position $A_{1}$ are slightly lower than the test results, but the trend of change is still consistent. It can be 


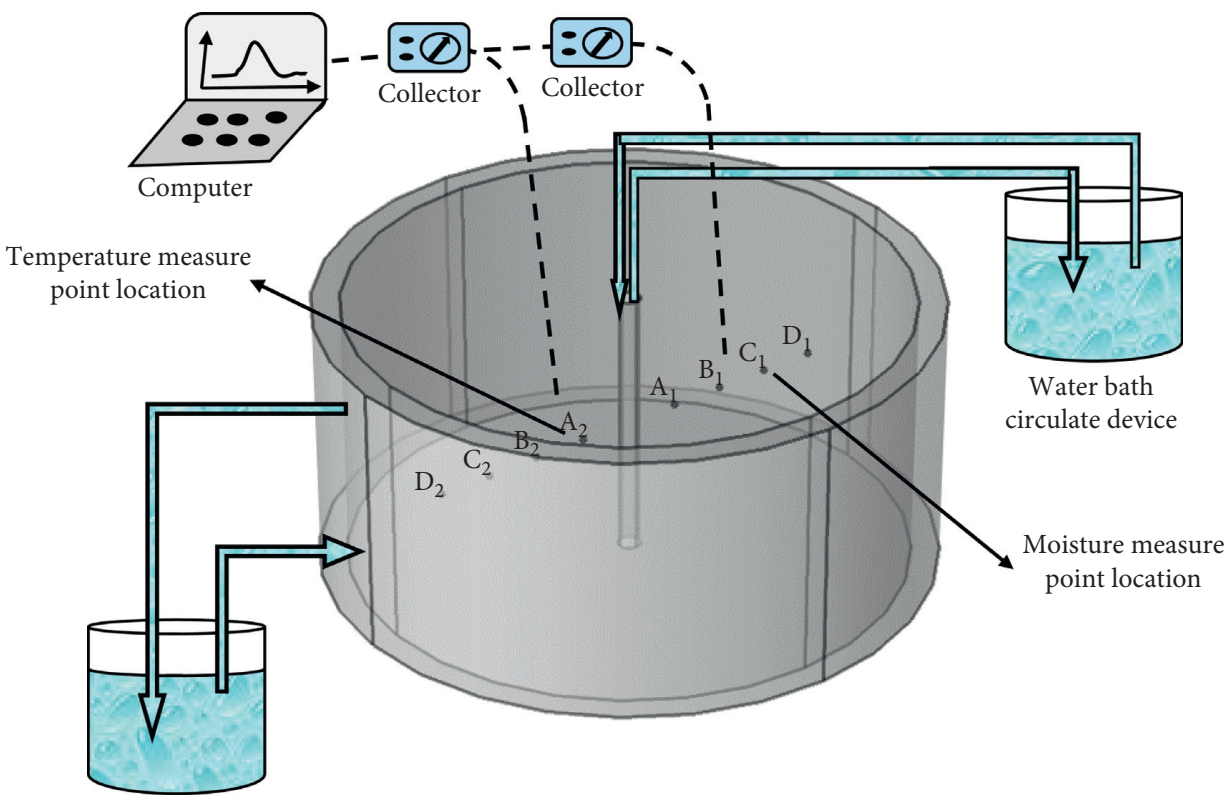

Water bath circulate device

Figure 1: Schematic diagram of the test device.

TABLE 1: Related physical parameters of kaolin.

\begin{tabular}{lccccc}
\hline Processing type & Density $\left(\mathrm{g} / \mathrm{cm}^{3}\right)$ & Colour & Refractoriness & $\mathrm{SiO}_{2}$ content (\%) & Molecular weight \\
\hline Water wash & 2.56 & White & 1700 & 52 & 258.16 \\
\hline
\end{tabular}

TABle 2: Test schemes.

\begin{tabular}{lccccc}
\hline Serial number & Initial saturation & Initial volumetric water content & $T_{\text {in }}\left({ }^{\circ} \mathrm{C}\right)$ & $T_{\text {out }}\left({ }^{\circ} \mathrm{C}\right)$ & Dry density $\left(\mathrm{g} / \mathrm{cm}^{3}\right)$ \\
\hline 1 & 0.47 & 0.196 & $\begin{array}{l}80 \text { (heating) } \\
25 \text { (cooling) }\end{array}$ & 25 & 1.5 \\
\hline 2 & 0.29 & 0.120 & $\begin{array}{l}80 \text { (heating) } \\
25 \text { (cooling) }\end{array}$ & 25 & 1.5 \\
\hline
\end{tabular}

TABle 3: Model parameters.

\begin{tabular}{lccccccccc}
\hline Parameter & $\begin{array}{c}\rho_{s 0} \\
\mathrm{~g} / \mathrm{cm}^{3}\end{array}$ & $\begin{array}{c}E \\
\mathrm{MPa}\end{array}$ & $a_{1}$ & $a_{2}$ & $\begin{array}{c}k_{s} \\
\mathrm{~W} /(\mathrm{m} \cdot \mathrm{K})\end{array}$ & $\begin{array}{c}\mathrm{K} \\
\mathrm{m}^{2}\end{array}$ & $\begin{array}{c}c_{p s} \\
\mathrm{~J} /(\mathrm{kg} \cdot \mathrm{K})\end{array}$ & $\begin{array}{c}\beta_{T} \\
1 / \mathrm{K}\end{array}$ & $\begin{array}{c}\beta_{M} \\
\text { Value }\end{array}$ \\
\hline
\end{tabular}

observed that when the parameter $\alpha$ does not change during the heating and cooling process $\left(\alpha_{1}=\alpha_{2}=1.89 \mathrm{~m}^{-1}\right)$ by comparing Figures 4(a) and 4(b), the calculation results present that the content of volumetric water at each location after the heating and cooling process has little change from the initial state and is far from the test result (Figure 4(a)). When the parameter $\alpha$ is set differently during the heating and cooling process (e.g., $\alpha_{1}=1.89 \mathrm{~m}^{-1}$ and $\left.\alpha_{2}=1.93 \mathrm{~m}^{-1}\right)$, the calculation results show that the volumetric water content at each location after the heating and cooling process is lower than the initial state and closer to the test results (Figure 4(b)).
Figure 5 shows the comparison between the test results and the calculated results of the temperature at different monitoring positions in the soil for cases 1 and 2. In the calculation process, the parameter $\alpha$ of case 1 is set to $\alpha_{1}=1.89 \mathrm{~m}^{-1}$ and $\alpha_{2}=1.93 \mathrm{~m}^{-1}$, and the parameter $\alpha$ of case 2 is set to $\alpha_{1}=1.89 \mathrm{~m}^{-1}$ and $\alpha_{2}=1.94 \mathrm{~m}^{-1}$. By comparison, it can be seen that the numerical calculation results of the temperature changes at each measuring point during the heating process of the two cases are in good agreement with the test results, but there is a certain gap during the cooling process. This is due to the errors in the parameters and boundary conditions of the laboratory experiments and numerical calculations. 


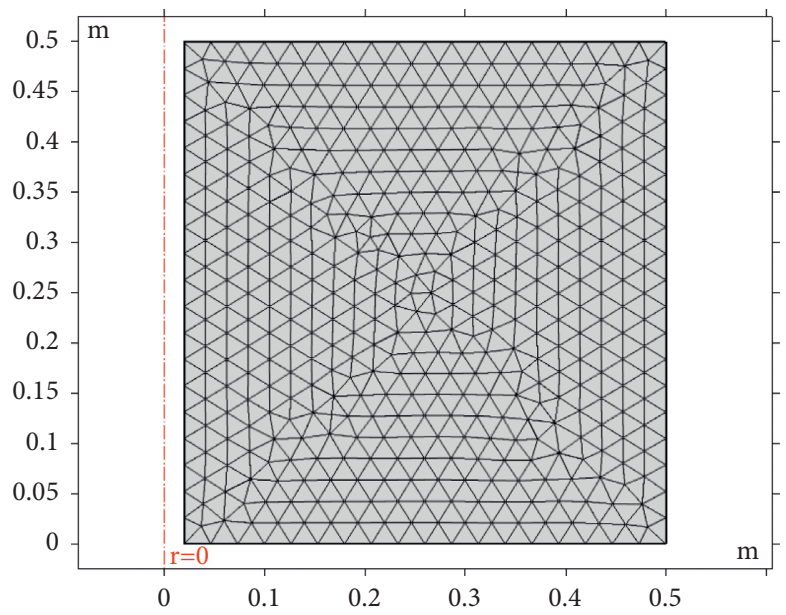

Figure 2: The meshing of the computational model.

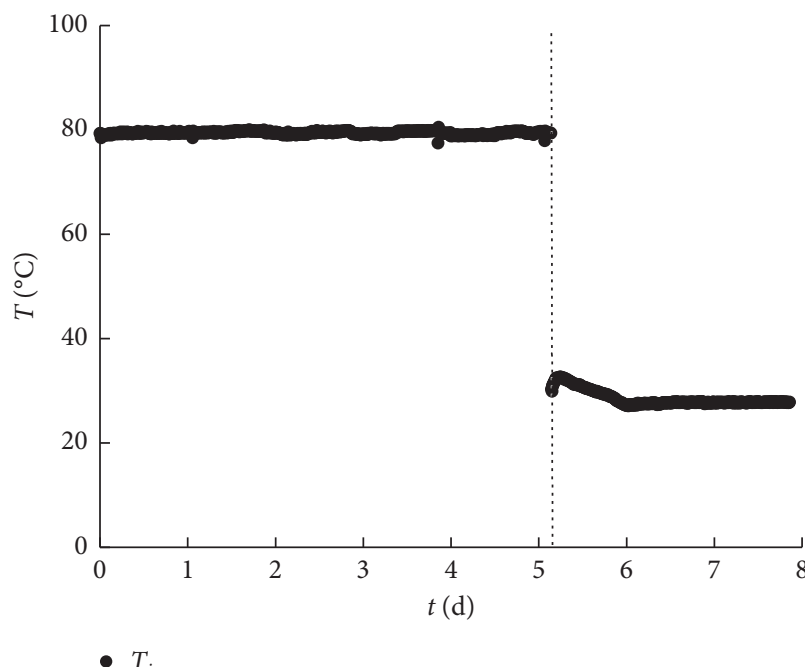

(a)

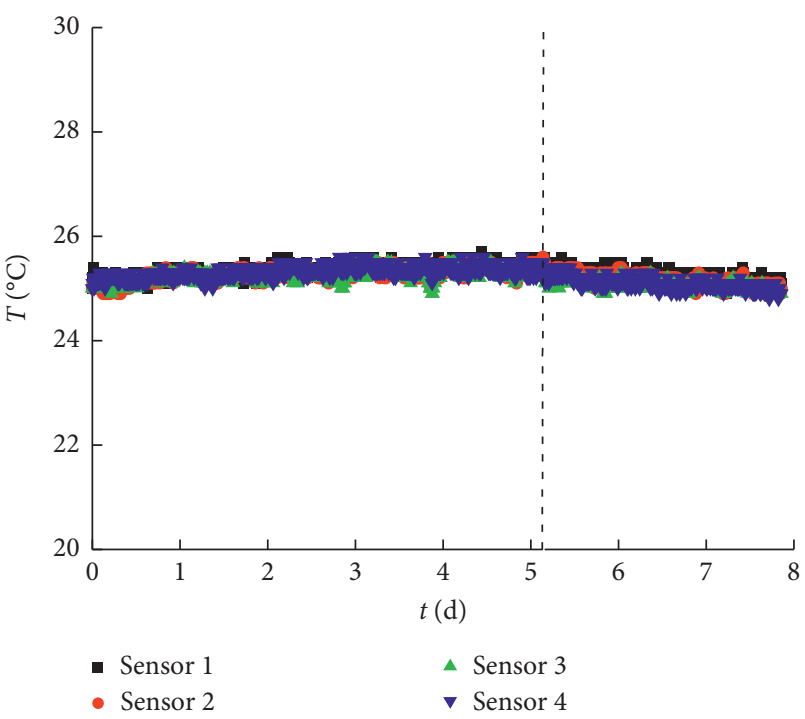

(b)

FIGURE 3: Variation of (a) heat source temperature and (b) boundary temperature with time.

Figure 6 shows the comparison between the test results and the calculated results of the volumetric water content at different monitoring positions in the soil for case 2 . Through comparison, it can be observed that the calculation results are consistent with the experimental results. In the calculation process, the parameter $\alpha$ is set to $\alpha_{1}=1.89 \mathrm{~m}^{-1}$ and $\alpha_{2}=1.94 \mathrm{~m}^{-1}$, and the initial pore water pressure and pore gas pressure are set to $1.56 \times 105 \mathrm{~Pa}$ and $1.46 \times 105 \mathrm{~Pa}$, respectively. The permeability $K$ in saturated soil is set to $4 \times 10^{-19} \mathrm{~m}^{2}$. It can be observed from Figure 6 that the numerical calculation results in the heating process are in good agreement with the test results, while the calculation results of the measuring points $B_{1}, C_{1}$, and $D_{1}$ in the cooling process have a certain deviation compared with the test results.

Figure 7 shows the distribution of saturation degree in the soil for case 2 when $t$ is equal to $1 \mathrm{~d}$ (heating process) and when $t$ is equal to $5.5 \mathrm{~d}$ (cooling process). It can be seen from Figure 7 that the bottom saturation degree of the soil, due to gravity effect, is higher than the top saturation degree; that is, the pore water pressure at the bottom is greater. The saturation degree near the inner heat source is almost lower than that of other locations, indicating that pore water migrates from the inside to the outside due to the thermal driving 


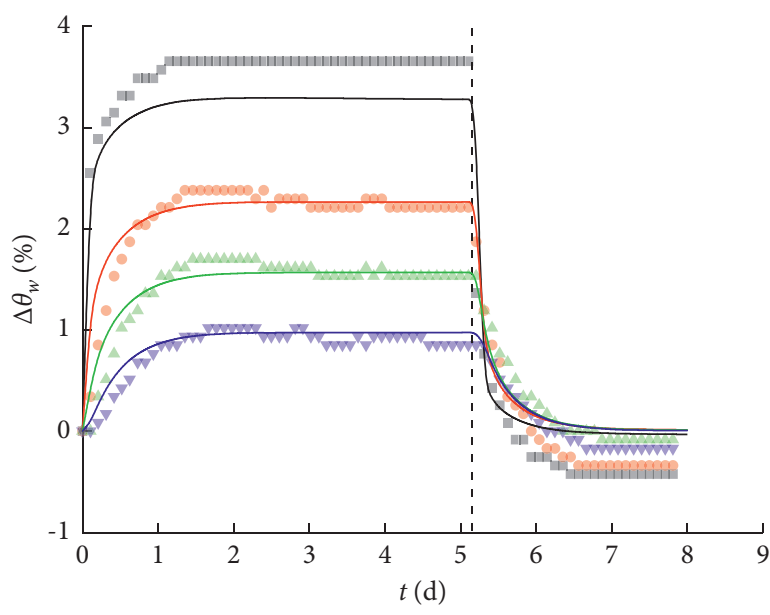

$$
\begin{aligned}
& \alpha_{1}=\alpha_{2}=1.89 \mathrm{~m}^{-1} \\
& \text { - } \mathrm{A}_{1} \text { Tested result } \\
& \text { - } \mathrm{A}_{1} \text { Calculated result } \\
& \text { - } \mathrm{B}_{1} \text { Tested result } \\
& \text { - } \mathrm{B}_{1} \text { Calculated result } \\
& \text { A } \mathrm{C}_{1} \text { Tested result } \\
& \text { - } \mathrm{C}_{1} \text { Calculated result } \\
& \checkmark \quad D_{1} \text { Tested result } \\
& \text { - } \mathrm{D}_{1} \text { Calculated result }
\end{aligned}
$$

(a)

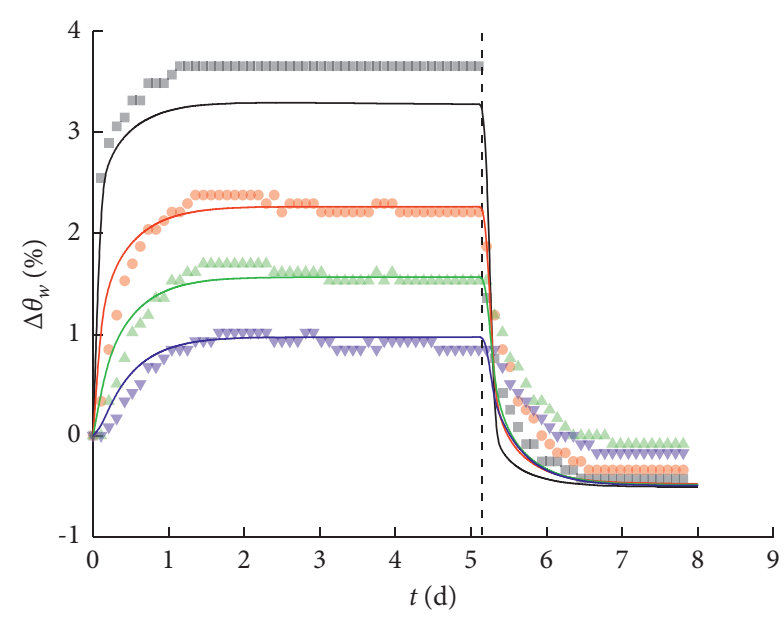

$$
\begin{aligned}
& \alpha_{1}=1.89 \mathrm{~m}^{-1} \alpha_{2}=1.93 \mathrm{~m}^{-1} \\
& \text { - } \mathrm{A}_{1} \text { Tested result } \quad \Delta \quad \mathrm{C}_{1} \text { Tested result } \\
& -A_{1} \text { Calculated result }-C_{1} \text { Calculated result } \\
& \text { - } \mathrm{B}_{1} \text { Tested result } \quad \nabla \mathrm{D}_{1} \text { Tested result } \\
& -\mathrm{B}_{1} \text { Calculated result } \quad-\mathrm{D}_{1} \text { Calculated result }
\end{aligned}
$$

(b)

Figure 4: Comparison of the volumetric water content with numerical calculation in case 1 : (a) $\alpha_{1}=\alpha_{2}=1.89 \mathrm{~m}^{-1}$; (b) $\alpha_{1}=1.89 \mathrm{~m}^{-1}$ and $\alpha_{2}=1.93 \mathrm{~m}^{-1}$.

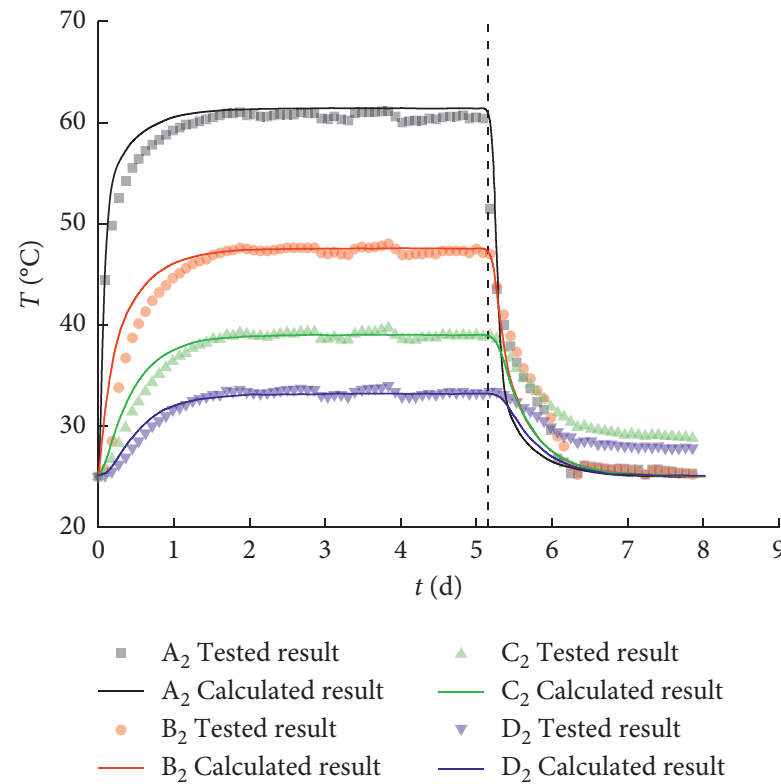

(a)

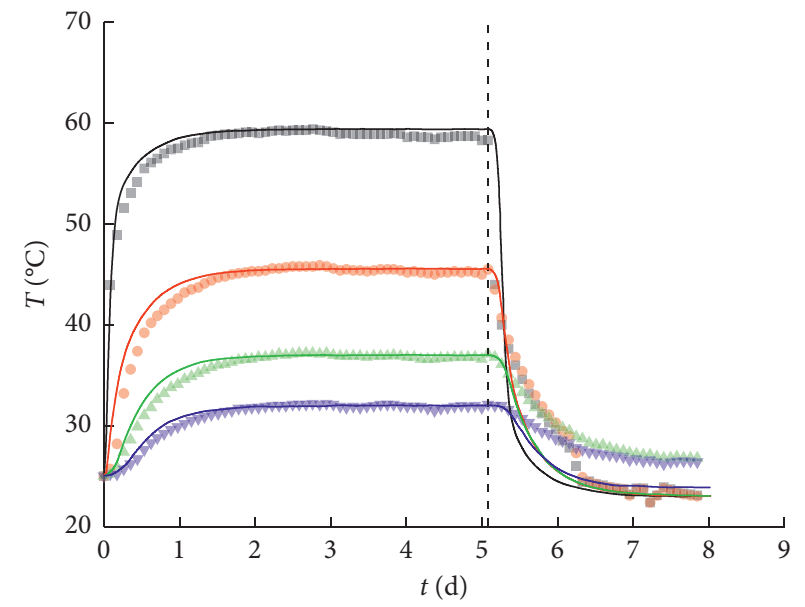

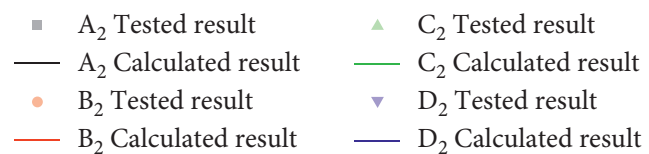

(b)

Figure 5: Comparison of results of temperature with numerical calculations in case 1 : (a) $\alpha_{1}=1.89 \mathrm{~m}^{-1}$ and $\alpha_{2}=1.93 \mathrm{~m}^{-1}$; (b) $\alpha_{1}=1.89 \mathrm{~m}^{-1}$ and $\alpha_{2}=1.94 \mathrm{~m}^{-1}$.

effect. During the heating process, the saturation degree of the soil showed a cone-shaped distribution with a narrow top and a wide bottom, while during the cooling process, the saturation degree of the soil showed a funnel-shaped distribution with a wide top and a narrow bottom. Besides, and the direction of the pore water pressure gradient during the cooling process is from the bottom close to the boundary to the top close to the heat source. 


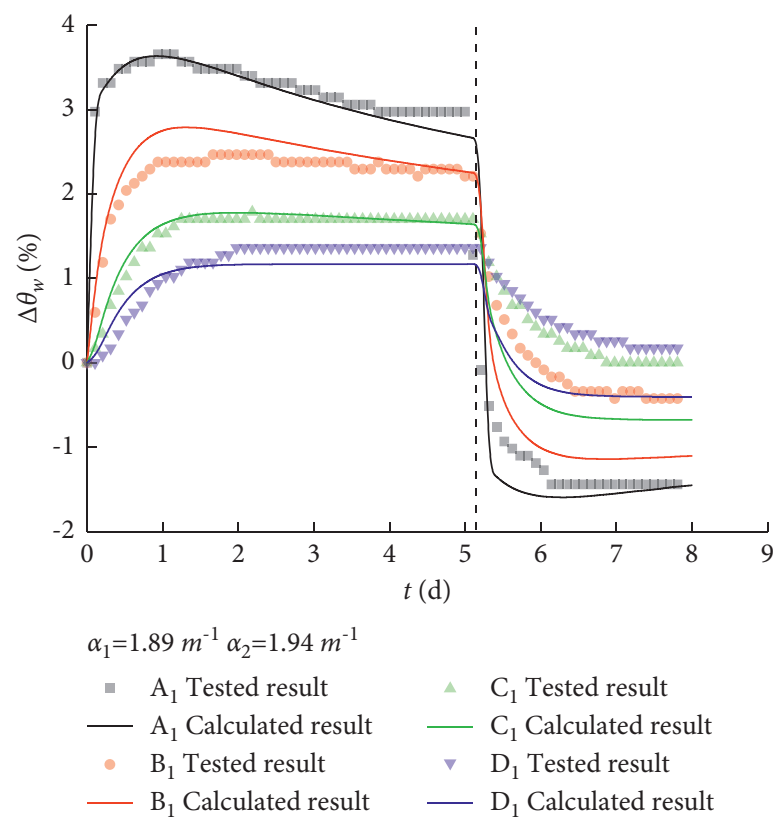

FIgURE 6: Comparison of results of the volumetric water content with numerical calculation in case 2.

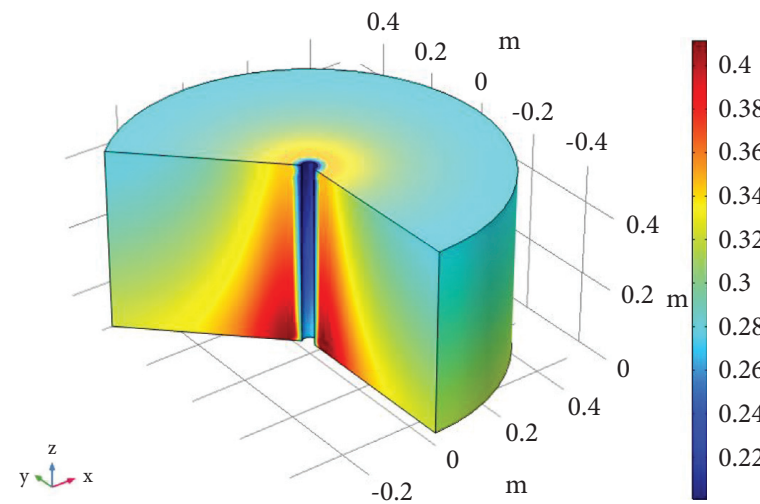

(a)

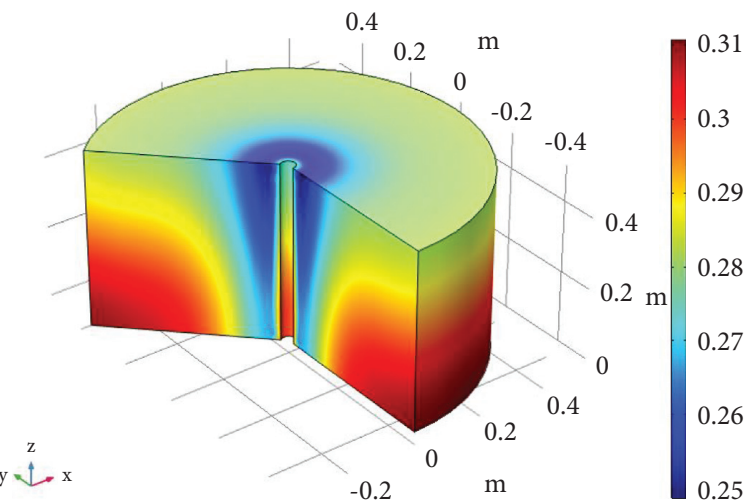

(b)

FIgURE 7: Saturation distribution in the soil: (a) $t=1 \mathrm{~d}$ during the heating process; (b) $t=5.5 \mathrm{~d}$ during the cooling process.

\section{Conclusion}

For unsaturated porous media, the governing equations of the three-field coupling effect of thermo-hydromechanical were established based on the theory of thermodynamics and thermoelasticity. The corresponding state equations were given, and each state variable was adopted according to the temperature-dependent nonlinear expressions.

A self-developed test device was utilized to discuss the hydrothermal coupling effects of two cases of unsaturated kaolin under the same temperature load. The test results were compared with the numerical calculation results. The calculation results at different positions are in good agreement with the test results, which shows that the established theoretical model is able to simulate the water-heat coupling process of unsaturated soils.
Different initial saturation degrees have little effect on the change of temperature over time. Compared with the process of moisture migration, the temperature reaches a steady state faster. The characteristics of moisture migration during the temperature rise and fall process are more complicated. When the initial saturation degree of the soil is high, the volumetric water content of the measuring point during the heating process increases, and then it is in a stable state; when the initial saturation is low, the volumetric water content near the heat source increases firstly and then decreases. The volumetric water content of the soil undergoes an irreversible process during the temperature rising and falling process. The test results indicate that the volumetric water content of the measuring point after the temperature rising and falling process is lower than the initial state. 


\section{Data Availability}

The data are available from the corresponding author upon reasonable request.

\section{Conflicts of Interest}

The authors declare that there are no conflicts of interest regarding the publication of this manuscript.

\section{Authors' Contributions}

Wei Wang conceptualized the study and provided the methodology. Jingjing Liu and Jing Chen investigated the study.

\section{Acknowledgments}

Funding for this research was provided by the Beijing Natural Science Foundation (8222023).

\section{References}

[1] B. Bai, T. Xu, Q. Nie, and P. Li, “Temperature-driven migration of heavy metal $\mathrm{Pb}^{2+}$ along with moisture movement in unsaturated soils," International Journal of Heat and Mass Transfer, vol. 153, Article ID 119573, 2020.

[2] P. Olasolo, M. C. Juárez, M. P. Morales, S. D'Amico, and I. A. Liarte, "Enhanced geothermal systems (EGS): a review," Renewable and Sustainable Energy Reviews, vol. 56, pp. 133144, 2016.

[3] G.-s. Yang, Y.-m. Liu, Y.-f. Gao, J. Li, and G.-q. Cai, "Coupled thermo-hydro-mechanical process in buffer material and selfhealing effects with joints," Journal of Central South University, vol. 28, no. 9, pp. 2905-2918, 2021.

[4] H. Li, K. Nagano, and Y. Lai, "Heat transfer of a horizontal spiral heat exchanger under groundwater advection," International Journal of Heat and Mass Transfer, vol. 55, no. 23-24, pp. 6819-6831, 2012.

[5] X. Chen, W. Pao, S. Thornton, and J. Small, "Unsaturated hydro-mechanical-chemical constitutive coupled model based on mixture coupling theory: hydration swelling and chemical osmosis," International Journal of Engineering Science, vol. 104, pp. 97-109, 2016.

[6] Y. Chen, C. Zhou, and L. Jing, "Modeling coupled THM processes of geological porous media with multiphase flow: theory and validation against laboratory and field scale experiments," Computers and Geotechnics, vol. 36, no. 8, pp. 1308-1329, 2009.

[7] J. Rutqvist, L. Börgesson, M. Chijimatsu et al., "Thermohydromechanics of partially saturated geological media: governing equations and formulation of four finite element models," International Journal of Rock Mechanics and Mining Sciences, vol. 38, no. 1, pp. 105-127, 2001.

[8] J. Chen, J. W. Hopmans, and M. E. Grismer, "Parameter estimation of two-fluid capillary pressure-saturation and permeability functions," Advances in Water Resources, vol. 22, no. 5, pp. 479-493, 1999.

[9] W. Wu, X. Li, R. Charlier, and F. Collin, "A thermo-hydromechanical constitutive model and its numerical modelling for unsaturated soils," Computers and Geotechnics, vol. 31, no. 2, pp. 155-167, 2004.
[10] G. A. Akrouch, M. Sánchez, and J.-L. Briaud, "An experimental, analytical and numerical study on the thermal efficiency of energy piles in unsaturated soils," Computers and Geotechnics, vol. 71, pp. 207-220, 2016.

[11] J. Ghorbani, M. Nazem, and J. P. Carter, "Numerical modelling of multiphase flow in unsaturated deforming porous media," Computers and Geotechnics, vol. 71, pp. 195-206, 2016.

[12] B. Bai, "Thermal response of saturated porous spherical body containing a cavity under several boundary conditions," Journal of Thermal Stresses, vol. 36, no. 11, pp. 1217-1232, 2013.

[13] R. Caulk, L. Scholtes, M. Krzaczek, and B. Chareyre, "A porescale thermo-hydro-mechanical model for particulate systems," Computer Methods in Applied Mechanics and Engineering, vol. 372, Article ID 113292, 2020.

[14] Y. Takayama, S. Tachibana, A. Iizuka, K. Kawai, and I. Kobayashi, "Constitutive modeling for compacted bentonite buffer materials as unsaturated and saturated porous media," Soils and Foundations, vol. 57, no. 1, pp. 80-91, 2017.

[15] Y. J. Zeng, Z. B. Su, L. Wan, and J. Wen, "A simulation analysis of the adjective effect on evaporation using a twophase heat and mass flow model," Water Resources Research, vol. 47, no. 10, Article ID W10529, 2011.

[16] B. Bai, "Fluctuation responses of saturated porous media subjected to cyclic thermal loading," Computers and Geotechnics, vol. 33, no. 8, pp. 396-403, 2006.

[17] N. An, S. Hemmati, and Y. Cui, "Numerical analysis of soil volumetric water content and temperature variations in an embankment due to soil-atmosphere interaction," Computers and Geotechnics, vol. 83, pp. 40-51, 2017.

[18] C. Zhou and C. W. W. Ng, "A thermomechanical model for saturated soil at small and large strains," Canadian Geotechnical Journal, vol. 52, no. 8, pp. 1101-1110, 2015.

[19] B. Bai, S. Jiang, L. Liu, X. Li, and H. Wu, "The transport of silica powders and lead ions under unsteady flow and variable injection concentrations," Powder Technology, vol. 387, pp. 22-30, 2021.

[20] R. Taherdangkoo, A. Tatomir, M. Taherdangkoo, P. Qiu, and M. Sauter, "Nonlinear autoregressive neural networks to predict hydraulic fracturing fluid leakage into shallow groundwater," Water, vol. 12, no. 3, p. 841, 2020.

[21] C. Cui, K. Meng, C. Xu, Z. Liang, H. Li, and H. Pei, "Analytical solution for longitudinal vibration of a floating pile in saturated porous media based on a fictitious saturated soil pile model," Computers and Geotechnics, vol. 131, p. 103942, 2021.

[22] M. T. van Genuchten, "A closed-form equation for predicting the hydraulic conductivity of unsaturated soils," Soil Science Society of America Journal, vol. 44, no. 5, pp. 892-898, 1980.

[23] B. Bai, L. Guo, and S. Han, "Pore pressure and consolidation of saturated silty clay induced by progressively heating/ cooling," Mechanics of Materials, vol. 75, pp. 84-94, 2014.

[24] R. Taherdangkoo, Q. Liu, Y. Xing et al., "Predicting methane solubility in water and seawater by machine learning algorithms: application to methane transport modeling," Journal of Contaminant Hydrology, vol. 242, p. 103844, Article ID 103844, 2021.

[25] W.-C. Cheng, Z. Duan, Z.-F. Xue, and L. Wang, "Sandbox modelling of interactions of landslide deposits with terrace sediments aided by field observation," Bulletin of Engineering Geology and the Environment, vol. 80, no. 5, pp. 3711-3731, 2021.

[26] B. Bai, F. Long, D. Rao, and T. Xu, "The effect of temperature on the seepage transport of suspended particles in a porous 
medium," Hydrological Processes, vol. 31, no. 2, pp. 382-393, 2017.

[27] X. Wang, H. Shao, J. Hesser, C. Zhang, W. Wang, and O. Kolditz, "Numerical analysis of thermal impact on hydromechanical properties of clay," Journal of Rock Mechanics and Geotechnical Engineering, vol. 6, no. 5, pp. 405-416, 2014.

[28] R. F. Charles and W. M. James, "Geothermal reservoir simulation 1. Mathematical models for liquid-dominated and vapor-dominated hydrothermal system," Water Resources Research, vol. 15, no. 1, pp. 23-30, 1979.

[29] K. Meng, C. Cui, Z. Liang, H. Li, and H. Pei, "A new approach for longitudinal vibration of a large-diameter floating pipe pile in visco-elastic soil considering the three-dimensional wave effects," Computers and Geotechnics, vol. 128, p. 103840, 2020.

[30] B. Bai, Q. Nie, Y. Zhang, X. Wang, and W. Hu, "Cotransport of heavy metals and $\mathrm{SiO}_{2}$ particles at different temperatures by seepage," Journal of Hydrology, vol. 597, Article ID 125771, 2021.

[31] W. Cheng, X. Bai, B. B. Sheil, G. Li, and F. Wang, "Identifying characteristics of pipejacking parameters to assess geological conditions using optimisation algorithm-based support vector machines," Tunnelling and Underground Space Technology, vol. 106, Article ID 103592, 2020.

[32] R. Taherdangkoo, A. Tatomir, and M. Sauter, "Modeling of methane migration from gas wellbores into shallow groundwater at basin scale," Environmental Earth Sciences, vol. 79 , no. 18 , p. $432,2020$.

[33] B. Bai and T. Li, "Irreversible consolidation problem of a saturated porothermoelastic spherical body with a spherical cavity," Applied Mathematical Modelling, vol. 37, no. 4, pp. 1973-1982, 2013.

[34] B. Yuan, Z. Li, Z. Zhao, H. Ni, Z. Su, and Z. Li, "Experimental study of displacement field of layered soils surrounding laterally loaded pile based on transparent soil," Journal of Soils and Sediments, vol. 21, no. 9, pp. 3072-3083, 2021.

[35] W. Hu, W. Cheng, S. Wen, and K. Yuan, "Revealing enhancement and degradation mechanisms affecting calcite precipitation in EICP process," Frontiers in Bioengineering and Biotechnology, Article ID 750258, 2021.

[36] B. Bai, Q. Nie, H. Wu, and J. Hou, "The attachment-detachment mechanism of ionic/nanoscale/microscale substances on quartz sand in water," Powder Technology, vol. 394, pp. 1158-1168, 2021.

[37] J. Bear and Y. Bachmat, Introduction to Modeling of Transport Phenomena in Porous media, pp. 550-558, Kluwer Academic Publisher, Netherlands, 1991.

[38] W. Hu, W. Cheng, S. Wen, and M. M. Rahman, "Effects of chemical contamination on microscale structural characteristics of intact loess and resultant macroscale mechanical properties," Catena, vol. 203, Article ID 105361, 2021.

[39] B. Bai and X. Shi, "Experimental study on the consolidation of saturated silty clay subjected to cyclic thermal loading," Geomechanics and Engineering, vol. 12, no. 4, pp. 707-721, 2017.

[40] C. R. Faust and J. W. Mercer, "Geothermal reservoir simulation: 1. Mathematical models for liquid- and vapor-dominated hydrothermal systems," Water Resources Research, vol. 15, no. 1, pp. 23-30, 1979.

[41] D. W. Pollock, "Simulation of fluid flow and energy transport processes associated with high-level radioactive waste disposal in unsaturated alluviumfluid flow and energy transport processes associated with high-level radioactive waste disposal in unsaturated alluvium," Water Resources Research, vol. 22, no. 5, pp. 765-775, 1986.
[42] B. Yuan, Z. Li, Z. Su, Q. Luo, M. Chen, and Z. Zhao, "Sensitivity ofmultistage fill slope based onfinite element model," Advances inCivil Engineering, vol. 2021, Article ID 6622936, 13 pages, 2021.

[43] I. Tsagareli, "Solution of boundary value problems of thermoelasticity for a porous disk with voids," Journal of Porous Media, vol. 23, no. 2, pp. 177-185, 2020.

[44] B. Bai and Z. Su, "Thermal responses of saturated silty clay during repeated heating-cooling processes," Transport in Porous Media, vol. 93, no. 1, pp. 1-11, 2012.

[45] S. Lu, T. Ren, Y. Gong, and R. Horton, "An improved model for predicting soil thermal conductivity from water content at room temperature," Soil Science Society of America Journal, vol. 71, no. 1, pp. 8-14, 2007.

[46] J. Côté and J.-M. Konrad, "A generalized thermal conductivity model for soils and construction materials," Canadian Geotechnical Journal, vol. 42, no. 2, pp. 443-458, 2005.

[47] B. Bai, D. Rao, T. Xu, and P. Chen, "SPH-FDM boundary for the analysis of thermal process in homogeneous media with a discontinuous interface," International Journal of Heat and Mass Transfer, vol. 117, pp. 517-526, 2018.

[48] X. Bai, W. Cheng, D. Ong, and G. Li, "Evaluation of geological conditions and clogging of tunneling using machine learning," Geomechanics and Engineering, vol. 25, no. 1, pp. 59-73, 2021.

[49] G. Yang, "Thermo-hydro-mechanical model for unsaturated clay soils based on granular solid hydrodynamics theory," International Journal of Geomechanics, vol. 19, no. 10, Article ID 04019115, 2019.

[50] R. Hu, Y. Chen, and C. Zhou, "Modeling of coupled deformation, water flow and gas transport in soil slopes subjected to rain infiltration," Science China Technological Sciences, vol. 54, no. 10, pp. 2561-2575, 2011.

[51] B. Bai, R. Zhou, G. Cai, W. Hu, and G. Yang, "Coupled thermo-hydro-mechanical mechanism in view of the soil particle rearrangement of granular thermodynamics," Computers and Geotechnics, vol. 137, no. 8, Article ID 104272, 2021.

[52] B. X. Yuan, Z. H. Li, Y. Chen et al., "Mechanical and microstructural properties of recycling granite residual soil reinforced with glass fiber and liquid-modified polyvinyl alcohol polymer," Chemosphere, vol. 268, Article ID 131652, 2021.

[53] B. Bai, G. Yang, T. Li, and G. Yang, "A thermodynamic constitutive model with temperature effect based on particle rearrangement for geomaterials," Mechanics of Materials, vol. 139, Article ID 103180, 2019.

[54] T. Hu, J. Min, and Y. Song, "Analysis of the effects of mass transfer on heat transfer in the process of moisture exchange across a membrane," Chinese Science Bulletin, vol. 55, no. 12, pp. 1221-1225, 2010.

[55] B. Bai, D. Rao, T. Chang, and Z. Guo, "A nonlinear attachment-detachment model with adsorption hysteresis for suspension-colloidal transport in porous media," Journal of Hydrology, vol. 578, Article ID 124080, 2019.

[56] V. A. Mirskaya, D. A. Nazarevich, and N. V. Ibavov, “Automated experimental facility to investigate a complex of thermophysical properties of liquids and gases," High Temperature, vol. 54, no. 2, pp. 223-228, 2016. 